\title{
Apuntes para la Vida de Alfredo González Prada.
}

\footnotetext{
Prólogo del libro "Redes - para captar la Nube", en el que se ha compilado Ia totalictad de-las obras de. Alfredo lonzález Prada.
}

Alfredo González-Prada nació en París, el i 6 de octubre de 189 I, durante el deliberado ostracismo de su padre, el insigne Don Manuel. Murió en también voluntaria proscripción, asqueado de miserias y dobleces, por propio designio, en Nueva York, el 27 de Junio de I943.

Por linea paterna descendía de una vieja e hidalga familia española cuyos papeles genēalógicos se conservan en la Biblioteca de la Universidad de Columbia, Nueva York, a la que fucron donados por Mrs. Elizabeth Howe González Prada, viuda de Alfredo, poco después de la muerte de éste y muy poco antes de la de aquella: que entre ambos decesos apenas transcurrió el lapso de diez meses. Uno de sus antepasados fué el Paje don Andrés González de Prada, secretario de don Juan de Austria - y ambos "víctimas de los celos, intrigas y maquinaciones del desleal Antonio Pérez y de su terrible amo el suspicaz Felipe II" - según la dedicatoria del libro "Antonio et Péres Philippe II" por M. Mignet (París, 1845 ), que obsequiaron a Alfredo cuando fué Ministro del Perú en Londres. Los Gonzáles de Prada conservaron su apellido hasta don. Manuel, que lo redujo, a partir de 
I87 I, a un democrático y simple "G. Prada". Alfredo siguió el hábito paterno. Aunque también tenía entre sus ancestros al famoso don Antonio de Ulloa, insigne marino y geógrafo, coautor de las célebres Noticias Secretas de Amé$c a$, prefirió ser hijo de su padre y de sus propias obras, antes que de la leyenda familiar. El que desee documentarse algo más, recurra, si lo tiene a bien, al capitulo primero de mi libro "Don Namuel", en donde resumo algunas noticias al respecto.

Por parte materna, Alfredo descendia de una señorial familia burguesa de Francia. Su abuelo, un abogado, tuvo altos puestos, y fué diplomático. Su tatarabuelo tuvo el rango de Fermier General del Rey.

Su madre, doña Adriana de Vernuil y Conchas nació en Villeroy, cerca de París, y vino al Perú a los diez años, esto es, en 1875 . Formaba parte de una casa de hombres de negocios. Se educó religiosamente, en un colegio católico, el de Belén - muy contra lo que se asevera Blanco-Fombona, que la hace miembro de una familia judía-, y practicó el catolici:mo hasta los dieciocho. Sigtuiósiende creyente. Pero, su gran crisis de irreligiosidad sobrevino abmorir su segrundo hijo casi en la cuna, del propio súbito modo que el primero. Por eso, apenas nacido Alfredo-sus padres estaban casados desde el I I de setiembre de 1887-doña Adriana pidió que no lo bautizaran ya que la doble tragedia anterior había ocurrido siempre poco después del bautizo de sus dos vástagos anteriores.

i Amor desesperado de madre amantísima, entonces, $y$ hasta ahora!.

Nacido en París, pudo Alfredo hacerse ciudadano francés. Don Manuel, que, contra lo comúnmente creído, era burlón y bienhumorado para los suyos, solia decir, acariciando la rubia cabeza del niño: "Si es inteligente se hará francés..." Fué tan inteligente como su pađre, y ambos vivieron en amor 
del Perí, inconmensurablemente. Pasión de mejorar y limpiar que les llevó al sacrificio de muchas cosas. Pero, ello se irá viendo mas adelante.

El niño creció mimado y celado, a causa de la tragedia de sus dos malogrados hermanitos-Cristina y Manuel-. En un concurso de belleza infantil, en Francia, la rubia cabeza y las rosadas mejillas de Alfredito recibieron un primer preinio.

Sólo conoció el Perú cuando iba a cumplir los siete años. Fué en i 898 . Coincidió con la época de mas dura lucha para su padre. Su hogar era vivero de debates transcedentales, de crítica acerba, de profunda paz doméstica. Aprendió su instrucción primaria en casa, teniendo como maestra a su madre.

Estudió la secundaria, desde los ocho en un colegio laico dirigido por alemanes: el Instituto de Lima. En 1906 cursaba el VI año de Instrucción Media. Entre sus compañeros de promoción figuran: Augusto Barreda y Laos, Héctor Boza Aizcorbe, Luis Bresani, Juan Coutourier, Nicolás Dora, René Dubreuil, Carlos Gađea, Arturo Jochamowitz, Sebastián Salinas Cossio, Augusto Leguía Swayne, Enrique Odriozola, Alfredo"Tôrfes Balcázar, Alberto Varela, Arturo Wells. Los que conocen la historia contemporánea del Perú, saben de algunos de estos nombres.

Como dato ilustrativo: en aquel año los estudiantes recibían dos horas semanales de Alemán, dos de Inglés, tres de Religión, tres de Gramática, dos de Ortografía, dos de Historia del Perú, dos de Historia Natural, dos de Geografía, dos de Gimnasia, cuatro de Aritmética, una de canto, dos de Dibujo. Alfredo hablaba francés en casa, como idioma nativo. Mas tarde, en su matrimonio, solía alternar inglés y francés para el trato con su esposa. Con su madre, siempre el francés. Con su padre, el castellano. 
No había cumplido los dieciscis, cuando ingresó a la Universidad Mayor de San Marcos, a la Facultad de Historia, Filosofía y Letras. Había decidido ser abogado y diplomático. Su madre queria que fuese médico: "En la Diplomacia tendrás muchas dificultades; tu padre ha atacado a casi todos los que la rigen". Pero, don Manuel tenía su propia experiencia de cuando sus padres trataron de hacerle seguir la carrera militar, la religriosa o la jurídica, y él acabó cradiendose del Colegrio de San Carlos. "No, déjalo hacer su voluntad; que él decida su destino". Lo decidió. Su matrícula tiene el número 1 , fecha 8 de marzo de 1907 , firmada por el Dr. Adolfo Villagarcía. Sus primeros cursos universitarios fueron los re Filosofía Subjetiva, Literatura Antigua, Historia de la Civilización Antigta y Literatura Castellana.

Su primer grado universitario, for recibió el 22 de julio de 1910 - justamente ocho años antes de la súbita muerte de su padre. Fué el de Bachiller en Letras. Su tesis versaba sobre Clemente Althaus, poetat del Perú. El diploma correspondiense está firmado por el Rector don l uis Felipe Villarán. el Decano doctor Adolfo Villagarcia, el Secretario de la Universidad, don Ricardo Aranda. y el Secretario de la Facultad, doctor Hildebrando Fuentes. Un ano desplues, ingresaba Alfredo al servicio diplomático, como amanuense del Archivo de Límites ( $r .^{\circ}$ de julio de Igir). Un sueldo de sesenta soles iba a premiar sus primeros desvelos internacionales.

El 3 de julio de IOI3, optó el grado de Bachiller en Jurisprudencia, bajo el rectorado del Dr. Lizardo Alzamora y el decanato del Dr. Eleodoro Romero. 'Ya hervía en el Perú la simiente revolucionaria social, acelerada por el gobierno de Billinghurst.

El I9 de noviembre del mismo año, recibía el diploma de Bachiller en Ciencias Políticas y Administrativas. Decano de esa Facultad era el Dr. José Matías Manzanilla. 
Coronó su carrera universitaria el zo de Noviembre de IgI4, con su tesis "El dercho y' cl animal", paral optar el grado de Doctor en Jurisprudencia. Era entonces Rector, el Dr. José Pardo, a quien se importó de Europa con el objeto de ponerle "en forma" para que reocupase la Presidencia de la República, lo que ocurriría un año desptés. En el examen de grado, Alfredo turo que absolver cuestiones como éstas: "El Patronito Nacional es un derecho inherente a la soberanía o una concesión graciosa del Sumo Pontificc?"; "El Sufragio": "El Colectinismo", etc. El I7 de Diciembre, Alfredo quedó inscrito en el registro de Abogados. Sólo en Iy 6 , el Is de setiembre, poco antes de partir para siempre al extranjero, recibió el grado de Doctor en Ciencias Politicas y Administrativas, bajo el rectorado del Dr. Javier frado. No tuwo más títulos acadénicos, sino hasta 1942 (2C de octubre) en que la Sociedad Pertuana de Historia de la Medicina de Lima, lo eligió Miembro honorario.

Ia vida universitaria de Alfredo fué brillante y ruidosa.

Era um mocetón alto $-\mathrm{r}$ metro 84 - fornido, rubio, de inquisidores ojos azules, agudisimo de pensaniento, de muchas lecturas, cuidadoso en el restir, con nu1 nombre ilustre, independiente de modos y conducta, enamoradizo, buen discutidor, fácil en la versificación, audaz en sus opiniones, periodista. E1 13 de agosto de 19 Io pronunció una brillante conferencia en Arequipa sobre el Centralismo Universitario, que apareció en "La Bolsa" de esa ciudad ( 20 de agosto de I9IO). Su nombre figuró entre los estudiantes que organizaron y dirigieron el III Congreso de Estudiantes de América, como delegado del Uruguay (I9I2). Fue uno de los lícteres de la expedición de estudiantes pertaanos a Panamá, er. Igr3. Formaba parte de un grupo literario que amenazaba la fúnebre paz de los valores consagrados: el do los 
"Colónidas", capitaneado por Valdelomar. Habia civienciado su valentía en varias oportuniclades. Asi, en Iota. cuando el coronel Benavides realizó la mascarada parlamentaria, merced a la cual fue ungido presidente provisorio, Alfredo, fiel a las enseñanzas de su padre, renunció su cargo en el Ministerio de Relaciones Exteriores ( 8 de mayo), dato publicado en "I a Prensa" de Lima. Reaccionando contra él, el Ministro Gazzani expidió un decreto "destituyéndolo". Alfredo retrucó por los diarios, en una brevísima carta en la que ratifica que había renunciado previamente y que era absurdo destituir a uno que se marcha por propia voluntad. Bastó eso para que, aprovechando otra coyuntura, le pusiera preso ( 3 de junio i914). La muchachada universitaria se declaró entonces en huelga. Alfredo quedó en libertad. Pero, ya habia visto con sus propios ojos, a qué extremo lleva la pasión a los hombres de cierta catadura en el Perú: le encerraron en el calabozo "Bolognesi" - "después el número 4"- - de la Intendencia de Policía, sin mas lecho que el suelo inmundo, y una ingrata compañia de ratas, chinches, pulgas- y eP incesante y enloquecedor rumor "de un cañol de agua que no dejaba de humedecer paredes y piso con alarmante pertinacia.

Aquella fué su primera renuncia. Fiel al credo de su padre, detestaba cuartelazos e imposiciones. No tardaría en increpar por la prensa la conducta del Ministro Gazzani que llegó a solicitar a Chile el confinamiento del caudillo peruano Durand, quien se hallaba refugiado y conspiranclo en Arica. El Perú que hasta entonces se había negado a aceptar ningún arreglo con Chile sobre la base de entregar todo o parte del territorio que jamás fuera cedido, aparecía reconociendo implícitamente la soberanía chilena al solicitar a sus autoridades proceder contra un refugiado perua- 
no. Durand no olvidó nunca el gesto de Alfredo. Alfredo no lo recordó jamás. Apenas, si en un libro de recortes suyos de entonces, encuentro unos cuantos datos.

Ia tesis sobre "El derccho y' el animal" promovio un verdadero escándalo. Prácticamente lo que ahí se decía era que el Cristianismo había retrogradado en este aspecto el espiritu del hombre, por cuanto los paganos amaban al animal. Un homenaje a Francisco de Asis reforzaba la tesis, haciendo del pozerctto fratcllo el primer cristiano de corazón unánime. Además, las citas juridicas desconcertaron al claustro. El decano, doctor Romero, se lo manifestó con toda franqueza. El catedrático doctor Diómedes Arias, le dijo palmeándole criollamente el hombro: "Oye, Pradita, tú nos estás tomando el pelo". Los jóvenes estudiantes y catedráticos se pusieron de parte del audaz graduando. El informe del doctor Juan Bautista de Lavalle aprueba la tesis, pero deja a salvo la opinión de la Facultad. El dia del grado. Alfredo fué paseado en hombros por el claustro. La prensa se ocupó del acontecimiento. José Enrique Rodó lo felicitó cordialmente por carta. $\mathrm{El}$ insistió en sus puntos de $v$ ista a través de artículos de prensacentonces- $y$, luego, en notas que hemos coleccionado y trascrito cuidadosamente. Una de ellas, de I942, está en inglés y ostenta trazos a lápiz que demuestran que Alfredo y su esposa colaboraron en aquella resurrección de antiguos puntos de vista.

\section{II}

Algunos encontrarán un poco exhaustiva la enumeración de datos referentes a Alfredo. No lo es. Ocurre que su vida tiene un significado hasta ahora inédito, tan inédito como su obra, que hoy empieza a salir a luz. Vida consagrada a servir, sin estridencia, pero fecunda por mil razones $y$ 
ecos: por lo que él llevó a cabo con sus manos: por lo que esas mismas manos hicieron pror las de los demais. Y, luego, encarnó tan justamente el estilo de su generación -y fue esa generación la que, con toda exactitud, marca el fin de una era y el principio de ofra en nuestra vida culturat, politica y literaria.

Demos, pues, a cáda dato el valor que corresponde. No es abuso de erudito, sino urgencia de situar cada hecho en su punto cabal, y repetir que Alfredo tiene un lugar inclisputable entre los pioneros de nuestra evolucion intelectual.

$Y$, por último, su vida y la de su grupo representa mutho que no debiera olvidarse ni mistificarse como estít empezando a ocurrir. .

Decía, pues, que Afredo ingresó a la correra diplomática antes de los 20 años, al par que cursaba sus estudios universitarios y daba comienzo a su vida de escritor. Con sesenta soles al mes, dije, fue nombrado Amanucnse del Archivo de Límites, el Io de julio de igri. Su madre no fue muy efusiva en la congratulación. Tampoco su padre. Pero, cada cual tiene su sino, y el fnuestroes respetar el de los otros.

Al llegar a la mayoria de edad, se inscribió en el Registro Militar lajo el número 32728, clase de i9i2.

El 3 de mayo del mismo año era ascendido a Auxiliar.

E] 8 cle mayo de 1914 , renunció, también lo dije, por no seguir sirviendo a una dictadura ocasionada en una mascaracla grotesca. Entonces vino la pseudo destitución, su rectificación, el apresamiento, la algarada juvenil, la libertad y la conjura. Mientras Don Manuel atacaba dónde y cóno podía al dictador, Alfredo andaba a salto de mata en pintorescos aquelarres de politiquería criolla. Puclo y debió ser entonces un lírler político. Pero había leído clemasiado a 
Feca de Queiroz, Anatole France, y Renán- y tenía frente a si la dramática experiencia de su propio padre, Apóstol ululante en un desierto de almas, transido de amor por quienes confundian amor con complicidad. Pudo y debió haber sido un líder político entonces, y más tarde. En muchas ocasiones lo tentaron. Ya se irá diciendo como hasta figuró como candidato potencial a la Presidencia de la República. Nc era su giro. El intelectual, acaso el dandy- (en su mejor sentido, por cierto) - que había en él, se negaba a toda intervención demasiado terrc-ì-tcre. $Y$ otros deberes le llamaban a menos árduas citas.

No salgamos de nuestro marco, por ahora.

Regresó al servicio, como Auxiliar del Archiro Especial de Limites, el I2 de Agosto de IgI6, siendo presidente don José Pardo. El 9 de setiembre le nombraban secretaric de segunda clase en la-Legación del Perú en Buenos Aires y Montevideo. Iba en la Misión que encabezó el Dr. Augusto Durand, legendario cabecilla revolucionario, jefe del Partido Liberal.

No diré aquí lo que Alfredo hizo y soñó en Buenos Aires. Prefiero, para que el lector ávido de informes concretos tenga los que le precisen, adelantar los hitos de su carrera diplomática, dejando para enseguida la peripecia del escritor. Así, pues, entre el 23 de junio y el 24 de octubre de 1917, desempeñó la Encargaduría de Negocios del Perí, en la Argentina- a los 26 años-; el 20 de setiembre del mismo I9I7 le ascendían a Primer Secretario; como tal, reocupó el cargo de Encargado de Negocios entre el 20 de abril de I9r 8 y el i 8 de febrero de I9I9, y entre el i9 de agosto de I919 - después de la revolución de Leguía- hasta el 2 de Mayo de I920. En este lapso sucedió la muerte de su padre. lo que alteró sustancialmente la existencia de Alfredo. En 
fin, el 2 I de Octubre de I020 fue nombrado Primer Secretario de la Embajada en Washington.

Con ello se iniciaba otra etapa de su vida. El año de I922 contrajo matrimonio en la capital norteamericana. $Y$, después de haber desempeñado varias veces la Encargaduria de Negrocios (de 5 de Marzo a 8 de Nityo de I022, de I 2 de Abril de I023 a 17 de Marzo de I024), file ascendido a Primer Consejero el 4 de Agosto de roz7.

E.n este interregno representó al Perú en numerosas asambleas internacionales, $y$ recibio diversas distinciones. Tengo a la vista el Diploma otorgindole la Merlalla del Centenario, 28 de Julio de I92I, con las firmas rlel Presidente Leguia y el Canciller Salomón: el de Oficial de la Orclen de "El Sol del Perú", otorgada el 30 de Setiembre de 1024, por el Canciller de la Orden Dr. Cesar A. Elguera; el de la Medalla de Plata conmemorativa del Primer Centenario de la Batalla de Ayacuho, firmado por Augusto B. Leguía y P. J. Rada y Gamio, el 9 de Junin de 1927 ; el de la Medalla de Oficial, firmado por los anteriores, el 25 de Julio de I927.

El Golsierno de Bélgicalo condecoróscon la Cruz de Caballero dc la Orden de la Coronacel 28 de Junio de 19i9, por su campaña en "La Prensa" de Lima.

El 9 de Agosto de I929 renunció a su cargo, - -segunda renuncia principista- despućs de un incidente del que se ocupó la prensa del mundo entero.

Ello le distanció del gobierno peruano, pero, sin deseos de hacer capital político, prefirió alejarse a Europa, en donde le sorprendió la noticia del derrocamiento de Leguía, un año después, y, estanclo en Estocolmo, con su esposa, la de su nombramiento primero como Agente conficlencial y, luego, como Enviado Extraordinario y Ministro Plenipotenciario ante el Imperio Británico. Este último lleva fecha de 
I9 de setiembre de I930, y está firmado por el comandante Luis M. Sánchez Cerro y el coronel Ernesto Montagne.

Alfredo fué designado, después, Presidente de la Delegación Peruana y Delegado ante la Liga de las Naciones.

Renunció a ambos cargos en diciembre de $193 \mathrm{I}$, a raiz de la constitución del nuevo gobierno del coronel Sánchez Cerro, quien, entonces abiertamente, se había entregado a manos del "civilismo" peruano, sempiterno enemigo de don Manuel González Prada. Era Ministro de Relaciones Exteriores, el Dr. Luis Miró Quesada, a quien don Manuel atacara clirectamente en cierta oportunidad.

Leal, como siempre, a la memoria de su padre, Alfredo abandonó su alta investidura y volvió a la vida privada. No saldría de ella: i9.32 señala el comienzo de su más intensa actividad como publicista.

Aún le tentaron con posibles nombramientos diplomáticos, $y$ hasta con postular su nombre a la Presidencia de la: República.

En el diario "Eh Sol"' de Lima, en recorte que tengo a la vista, sin fecha, pero de 19.3 I sin duda, se habla de "La llegada del Dr. Alfredo González Prada" falseando los hechos de un modo curioso, pues se le supone fundador del Aprismo y dispuesto a ir al Perú "a colaborar en el seno del partido en Lima", como "el nuevo líder que reorganizará el partido". De puño y letra de Alfredo hay una nota que interroga: “¿Pinillos-Dulanto, Dulanto-Pinillos?”. Posiblemente, alguien le remitió el suelto diciéndole que el señor Jorge Dulanto Pinillos, que entonces ejercía actividades periodísticas, habría sido autor del suelto.

Personalmente oí decir a un connotado político peruano, en 1934, que la de González-Prada habría sido la candidatura "ideal" en I93I. El comandante Gustavo A. Jiménez 
y algunos de sus amigos sureños la patrocinaron en una ocasión. A principios de r"3". "l.a Noche" y entos periódicos limeños afirmaron, sin fundamento, que Alfredo seria candiclato de unat coalición de izquierdas - y hasta me atribuyeron participación en ello. Entre las cartas de Aliredo he encontrado algunas sugestiones para que fuese al Perú a hacer politica o volviera a la diplonacia. En una de ellas. firmada por el prominerite banuluerw don fernando lliese. se le sugiere, (en I940) aceptar se le postulase como Embajador en Chile, cargo entonces vacante. Otra de Haya de la Torre lo felicitat por no haber accedido. Creo que Alfredo simplemente dejó de responder a las insinuaciones, $y$ rue deseaba ardientemente regresar al Perí, a obscrvar el ambiente, antes de decillirse a paso alguno. La guerra $-y$, luego su trágica muerte cortaron aquel proyecto y también sus planes literarios, ya antbiciosos de nuevo, como en los años juveniles.

\section{III}

Ia carrera Jiterariacle Alfredose cinicio desde muy niño, y culminó, durante su primera etapa, en "La Prensa" de Lima. Tenía apenas diez años cuando, en unión de su madre (que fue su maestra de escuela primaria, en casa, desde luego) compuso la primera edición de "Mimisculas" de don Manuel, edición rarisima de apenas too ejemplares numerados y dedicados. Tengo el que correspondió a Alfredo, derlicado por su madre.

En 1912, el Perú experimentó un inicio de transformación. La candirlatura Billinghurst, a cuyo lado estuvo Valdelomar, significa muchas cosas que no han sido bien determinadas todavía. La ciudad limeña empezalsa a ser eso 
que I.ucio I.ópez aplicó a Buenos Aires: "gran aldea". La nueva promoción estudiantil renegaba de lo universitario, pero utilizaba el claustro de San Marcos al par que la sala y escalinata del "Palais Concert" como estadio donde desarrollar sus energías.

Alfredo, que usaba el pseudónimo de "Ascanio", se lanzí contra muchos prestigios visibles e invisibles. Hace años preparo yo un libro sobre este periodo, y en él colaború mucho Alfredo. Aqui pretendo ceñirme sólo a cuanto a él concretamente se aplica.

"Ascanio" realizó, por lo menos, las siguientes proezas en aquella Lima empapada de timidez y colonialismo: promovió la polémica sobre pintura que escindió en dos alas a los intelectuales peruanos; exaltó a tres artistas, como medio de sacudir el sopor claustral: a Felyne Verbist, a Antonia Mercé y a Mercedes Padrosa consideró el teatro un natural modo de actividad literaria; modificó el estilo de las interviús; atacó ciertos dogmas esenciales sobre moral ascética; etc.; defendió, acicateó y definió la rebelión estudiantil contra un profesor, en nombre del derecho del universitario a darse o aceptar maestros eficientes," en fin promovió la publicación de "Colónida" y "Las Voces Múltiples".

A propósito de su tesis "El Derecho y cl animal", el flamante abogado Alfredo González Prada, (con estudio en Negreiros 536. Lima), recibió una calurosa carta de José Enrique Rodó (Con referencia en el presente volumen), ver-dadero espaldarazo al joven escritor. En ella Rodó confiesa, además, su pasmo ante la reacción que su "Cristo a la Jine$t a$ " hallara en un Obispo y una asamblea católicos del Perú. "Colónida", la revista de Valdelomar reprodujo la carta en su número inicial.

Con el artículo "La Exposición Oxandanberro", inserto en "La Prensa" hacia marzo de I9I5 (no tengo fecha en 
mi recorte), se origrino la más encendida prómica literaria. o, mejor aun, estetica de nuestros iltimos tiempess limenos. Contra Oxandanberro (impresionista catalin, hoy residente en (uayaquil), y contra Alfredo, saltis el critico de arte Téófilo Castillo, que defendia a cierto pintor arerentino, Iranciscovich, habil confeceionador de paisajes de uniforme cielo añil. Se agruparon al lado de Alfredo, Valdelomar. el jrven Nariátegui. Nore. los "colónidas"; y, junto a Castilio, Clemente Falma y los postmodernistas a semirrealistas. Desde entonces las tendencias guedaron mejor definidas, $y$ ariquirio espiritu de cuerpo la alegre gente literaria que lanzaba pullas, piropos, brutades y sonetos en la calle de Baguijano, entre el Palais Concerty "I.a Prensa".

"La extiaña sugestión de una mujer incógnita" narra el descubrimiento de la pianista Vercedes Padrosa, a quien impuso ante el júblicr".

En "Jl alumno, juca de su macstro" y los articulos smbsiguientes, - "La Gran Iuclga miversitaria", "Necesidad de Persistir", "Nucvos rumbos", (mayo de IgrG)-defendió a los alumnos de la Escuela de Ingenieros que se habian rebelado contra eb jrofesor Enrigue Silgado, y planteó la anómala situación de muchos profesores, en San Marcos, algunos de los cuales fueron, tres años desjués, cancelados por la revolución universitaria de I9I9. Eco de la activiclad de Alfredo en aquella coyuntura es una carta del presidente de la Asciación de Estudiantes de Ingenieria, Arturo Bartra, fecha el 6 de junio de IoI6 dirigida a Aliredo, en la que le comunica que la Asociación le habia tributado un "voto de aplauso por su valiosa cooperación en fro de la solución favorable del conflicto creado en nuestra Escuela el mes anterior". El i 3 de agosto de I9I9, en la sección "La perspectiza diaria" de "La Prensa", sobre la firma de Gas- 
ton Roger -el malogrado Ezequiel Balarezo Pinillos-. apareccía una nota sobre otra huclga estudiantil - la Grande-, y en ella se decía: "en este mismo diario, cuatro (?) años atrás, el distinguido y culto escritor que firmaba con "el seudónimo de "Ascanio", intentaba lo mismo: conmover "las almas jóvenes que estancara la rutina y la ignorancia "cn las aulas legendarias de la Universidad mas antigua de "la América".

Era. Alfredo en 1915-tors una especie de arbitcr dogantormm. Con un largo sobretodo color avellana, los lentes inquisidores, el bigotillo rubio rizado, la gran cabeza cubierta de copioso cabello dorado, aito, esbelto, otorgaba celebridad, como lo demostró con su artículo "Felyne Verbist, Media hora con la gran artista", y con su polémica en defensa de Herrera y Reissig, cuando escribió los artículos "Poesia al uso" que provocaron las iras de don Juan José Reynoso. de quien Aifredo se burló con cierta crueldad.

Una tarde —cuenta Colónida, número 4 , páginas $37 \mathrm{y}$ 38- en "La Prensa". en la oficina de Alfredo Gonzáiez Prada, "jerifalte fornido y rubio", aiterato 9 "poeta contra el que 1a Jurisprudencia tramaconspiradoras acechanzas se reunieron (un dia) el mismo Alfredo, Alberto Ulloa Sotomayor, Abraham Valdelomar, Pablo Abril y de Vivero, Federico More, Hernín Bellido y Antonio Garland". Esa vez resolvieron formar un libro de versos entre los ocho. "Como quien dispone un almuerzo de amigos, Alfredo dispuso que era preciso hacer el libro". Así nació "Las Voces Múltiples" (ed. Rosay, 19I6). El título se debió a él; iguaimente el contrato de edición. Cuando apareció el desigual y discutido volumen - testamento literario de una generación en agraz, uno de los comentarios menos comprensivos, pero, sin embargo más cordiales fué el de "El Mosquito", el famoso se- 
manario satírico de Florentino Alcorta. En lo referente a Aliredo, decia el terrible sagitario: "Pena me dá esto de ver al talentoso Ascanio codeándose en un mismo cajón con $A n$ tucos y Valccitos. Esto tiene, pues, meterse a poeta. . . Pcro, : se imagina Ascanin que realmente es pocta?. Pues se equivoca. Una cosa es tener talento $y$ hacer buena prosa, y otra muy diferente escribir poesias. . : Pero no es una pena que un escritor tan talentoso y culto como Ascanio se bote a ponerse en ridiculo por manera tan voluntaria como injustificada? Parece mentira". Fl objeto de la censura era el polirritmo "La Hora de la sancfre", publicado en Colóniia, una de las composiciones mas fuertes y serias, si el adjetivo cabe, de nuestra literatura contemporánea.

Sobre Alfredo pendian muchas vindictas, ansiosas de cebarse en su apellido, aprovechándose de su fuego juvenil.

Don Manuel, su padre, que nunca intervino en la obra literaria de Alfredo, sonreía de aquellas aparatosas discusiones y controversias.

No sonrió cuando supo que el donjuanismo de su vástago, señor de muchas conquistas, había florecido en dos chiquillos: una niñita y un varón. Aquella murió poco después; éste fue confiado, por decisión de Alfredo, cuando se embarcó hacia la Arg̣entina, a doña Adriana. Yo le conocí con esa sonrisa inefable, esos ojos negros luminosos, de soñador, ese rostro al último enjuto. Felipe anunciaba que en él se encerraba toda la savia de su estirpe. Murió, después de haber concluído sus estudios secundarios en el Colegio Anglo Peruano de Lima; murió en París, al lado cle su abuela. Yace sepulto en el cementerio de Pere Lachaise: aquello fue en I933. $Y$ yo bien se que, precisamente por muy callada, esta pena no se borró jamás del corazón de Alfredo. 


\section{$-21-$}

Volvamos a 1916. Alfredo salió, como se dijo, hacia Buenos Aires.

Ahí sigtió su actividad literaria. Un dato ilustrativo: insistió en su tópico, la defensa del animal, en conferencia dictadia en la "Sociedad protectora de Animales, Sarmiento".

En Lima se le recordaba siempre. Hacia 1918, "La $\mathrm{No}$ che" de Lima publicaba tres sonetos imitados, uno de ellos "a la manera de Alfredo González Prada", otro "A la maneril de Iuan Chroniqucur". El primero decía así:

\section{El soneto de la angustiosa sensación...}

Buenos Aires. A tantos. La Verbist ha tenido noticias del Perú.

Hemos hablado de ellas. (El anis espiritualizaba el ambigu).

Hiperdulicamente su monsieur claba una nota parisina $y$ mis pensamicntos fizgaban el frufru intermitenteide sutraje gris.

He sabido también porcel doctor

que nucstro excelentísimo señor cstá con el partido liberal.

$\mathrm{Y}$ recordando a Federico More, he sentido enseguida con horror que nuestro excelentísimo está mal.

Se me ha dicho que este soneto es obra de Federico More, o de Humberto del Aguila, o de Félix del Valle. Pudiera también ser obra de Luis Fernán Cisneros, por su facilidad para esta clase de imitaciones. No lo sé, y necesitaría volver al Perú para asegurarme de ello. En todo caso, la alusión al doctor es muy clara: se trata de Augusto Durand. 
Alfredo revelaba en sus versos la aguda influencia di Herrera y Reissig, su mayor admiración de entonces, sin duda alguna $-y$ mucho de Queiroz.

Trodo ello terminós el 22 de julir de 1o18. A la noticia de la mucrte de su padre. Alfredo urgio a su madre a que se le reuniera en Buenos Aires, y algo mas: que "de ninguna manera" dejara en Lima a Nani el perro predilecto de don Manuel.

Creo que ese dia murió hasta resucitar veinte años más tarde- Alfredos, el escritor. En cambio nació el publicista. consagrado con una lealtad feroz a la revelación de la olura inédita del Maestro.

No conozco, según tratare de hacer ver, ejemplo más grande de amor filial y agudeza crítica aplicada a un objetives tan concreto y circunscrito.

Antes de abandonar Buenos Aircs, Alfredo recibió numerosos homenajes. Uno de ellos fue of recido pror "sus compatriotas" se realizí en el Jockey Clul, el 23 de febrero de 1919. Como curiosidad, y para ilustración de los que se interesan por ciertos liusos, ctrascribe ela Menú integro: "Al "Doctorl Alfredog GoneúlczlliPradársosus compatriotas / "MENU / Viandes froides Riche / Filet de Pejerrey Maitre "d'Hotel / Oeufs poches Sarah Bernhard / Suprême de "Volaille Princesee / Omelette Surprise / Friandises/ "Fruits/Caf'/ Buenos Aires, 23 de Febrero rgro". El ejemplar que conozon lleva 20 firmas a lípiz. algunas ilegilles. Entre las legibles destaco la de Manuel Elías Bonnemaison, E. de la Lama, Carlos Gandolfo, Amador del Solar (embajador del Perú), G. Basombrío, J. F. Castro y P., Luis Aranda Paredes, J. Gutiérrez Madueño, E. Iópez Aldana, Jaime Vignat de Guerolles,

Tengo entendido que este banquete se realizó con motivo de que Alfredo iba a dejar de ser Encargado de Nego- 


\section{$-23-$}

cios, a causa del nombramiento del nuevo Embajador don Amador del Solar.

\section{IV}

A fines de 1920 llegó Aliredo a Washington, con el rango de Primer Secretario. Sé que, cuando venía a Nueva York, le gustaba visitar a amigos residentes en sabroso boarding houscs, para incrementar su inglés y para conocer el fonclo de la vida neoyorquina. En algunas cartas me hablaba de una de esas casas en que las inquilinas se mostraban singularmente pródigas, y hasta se equivocaban de pieza.

El Embajador peruano en Washington era don Federico Pezet, hombre de señoril barba y porte eminente, pero que, por desgracia, tuvo, al cabo de algún tiempo, disturbios y enredijos que dieron al traste con su representación y su carrera.

Uno de los mejores amigos que hizo Alfredo ahí fue un peruano por largo tiempo residente en Estados Unidos, lambién del personal de da Embajada: Juan Alvarez de Buenavista. Siempre le oí repetir que no podía pensar en aquel compañero, muerto hacia 1936 o algo asi, sin una profunda nostalgia.

En 1922 conoció Alfredo, en la alta sociedad washingtoniana a Elizabeth Anne Howe, una muchacha de vasta cultura, gentilísima silueta y extensas relaciones.

Descendia Elizabeth de cierto David Howe "a scion of a noble English family", llegado a Estados Unidos en I 700 , según veo en un amarillento recorte de periódico que tengo ante mi. David Howe edificó en el valle de Connecticut una hermosa mansión, que, cuando sus finanzas decrecieron, convirtió en posada o "Inn". Era una inmensa heredad. Los Howe, por orgullo no quisieron rotularla como lo que 
era, hasta que el Coronel Ezekiel Howe de lit tercera generacion plantís sobre su frontis el letrero "Red Horse Taz'ern". El Coronel se marchio enseguidit a la gruerra, mosquete al hombro. Hacia 18,30. J yman Howe la rencupris. Los Howe fucron poco prolíficos, por lo que sin habitantes el paraje adquirió cierto tinte melancrilico. De eso se aprowechi el insigne Longfellow para inspirarse. Sus "The Tales of a Wayside lm" tienen como escenario la Red Horse Tazern del "Squire" Eyman Howe, segitn el propio pretia lo declara en una carta dirigida a Mrs. James T. Field

Elizalueth nacida en Orange. $N$. Jersey, el 2 de octubre de 1895 . contaba, ademis. entre sus antecesores a utro famoso personaje: Harriet Beecher-Stowe, la autora de "La Cabaña dcl Tio Tom". De ella heredó, sin duda, cierta proclividad a la independencia mental $y$, acaso, su amor a $\mathrm{Alfr} \mathrm{r}^{-}$ do, gentilhombre de le jano pais, dueño de un nombre de pelea, ligado a las reivindicaciones sociales de su distante patria peruana.

El matrimonio se realizó en New York en la Iglesia de San Bartolomé el 16 de asrosto de di22. Las esquelas matrimoniales están encabezadas por los nombres de las respectivas madres, ambas viudas. La de Alfredo viaji especialmente del Perú a presenciar la boda de su unigénito. La de Elizabeth, Minie Lewis Howe, descendiente de una familia anglo-canadiense (los Lewis), usó el nombre de su difunto esposo, Mr. Emerson Howe. Los recién casados se embarcaron a Europa.

A mi me produce cierta emoción hablar de este matrimonio. Traté a Elizabeth en diversas circunstancias- en Chile, en Washington, en Cálifornia- y simpre la tuve por mujer de fino gusto y esencial adhesión a Alfredo. Este, a su turno, nunca dió que hablar acerca de su fidelidad 
conyugal. I.os amigos de juventud que le conocian enamoradizo, se admiraban de su monogamia a partir de 1922. En cien cartas Alfredo, cada vez que se ofrece me habla de Elizabeih, refiriendo algún comentario suyo, aludiendo a alguna lectura en comin.

Pur desgracia Elizabeth padecia de un asma incurable, de que le provenian espantosos ataques, que la colocaban a pique de la muerte. Alfredo vivió pendiente de esa enfermedad de su esposa hasta su último día. No dejaban de telefonearse, cuando estaban en distinta ciudad, por lo menos dos veces al día, y a menudo más. Huyendo de inviernos y veranos demasiado crudos que agotaban a Elizabeth, dieron la vuelta al mundo varias veces.

Cuando Alfredo murió, Elizabeth quedó tan postrada que, prácticamente, ya no supo como vivir. No quiso alejarse de su suegra, y tuvo en la mente la constante idea de aliviar la soledad desgarradora de doña Adriana. Yo la ví en su casa de Washington el 29 de marzo de 1943, para tratar con ella de la publicación de los papeles dedon Manuel y Alfredo, que deseabaJ continuar, como un deber básico. "Estoy deshecha - me dijo. I.a muerte de Alfredo me ha matado a mi también". "Me entregó un retrato de su marido y un libro de recortes. "Véalo, tan joven"-y sentí que no podía hablar mas. "Todo lo que tengo es para hacer lo que él hizo toda su vida". Me despedí de ella, y era una pavesita de pu-' ro frágil, y envejecida. Estaba yo en Enid, Oklahoma cuando recibí la noticia de la súbita muerte de Elizabeth: había ocurrido el 22 de abril, veinticuatro días después de que yo' la viera.

La víspera, en la noche - supe después- se había mostrado animosa, entusiasta con sus trabajos para la Cruz Roja. Su madre salió a una fiesta. Por la mañana nadie con- 
iestó cuando llamaron al cuarto de Elizabeth. Estaba tendida en el suelo, muerta, fria, absolutamente fria. Un ataque de asma la sorprendió a media noche sin darle tiempo a nada. Tenía, si no yerro, 48 años.

Retrocedamos un poco.

Alfredo tuvo que actuar en Washington como consejero $y$ enlace en las discusiones del asunto de Tacna $y$ Arica, entre Perú y Chile. Sobre esa etapa, dura y amarga, hay un archivo personal completo que, a su tiempo, seri conocido. Alfredo se opuso al rumbo de las negociaciones y presentó exposiciones. de una de las cuales hablí la prensa.

Cuando se firmó el tratado Figueroa Larrain-Rada y Samio, que puso remate al litigio, dividiendo el territorio disputado entre los dos contrincantes, el Presidente Leguia queriendo halagar a Chile, nombrí a Alfredo como Consejero de la primera embajada del Perú en Santiago. No olvidemos que su padre, don Manuel fue toda su vida el más encarnizado y tenaz apóstol de la revancha. Un González Prada en Chile sellaria simbólicamente la renovarla amistad. El decreto correspondiente le fue trascrito por nota numero 497 , fecha 3 de setiembre de 1928 , refrendada por don Samuel Barrenechea Raygada, Oficial Mayor del Ministerio. Dice así:

"Con fecha 29 de Agosto último, se ha expedido por este Ministerio, la siguiente Resolución Suprema:- Nómbrase Consejero de la Embajarla del Perú en Chile, al doctor don Alfredo González Prada, quien continuará disfrutando, durante el presente año, del haber que percibe como Consejero de la Embajada en los Estados Unidos de América.-Rúbrica del señor Presidente de la República. Rada y Gamio".

Alfredo no aceptó. Se lo cobrarían muy luego. 
El jueves I I de julio de 1929, el "Waskington Daily Post" lanzaba una vistosa información titulada: "Pcruzian Indian scriant acts pricate and Diplomatic Relations al! tangled" - y referia un episodio del que eran protagonistas principales Alfredo y Mrs. Elizabeth Gales Poindexter. esposa de Mr. Miles Poindexter, ex-embajador de EE.UU. en Lima.

Las cosas habían ocurrido como sigue.

A su regreso del Perú, los Poindexter habian llevado a Washington una pareja de criados mestizos peruanos, la misma que habian tenido por cinco años en Lima, y a la cual le pagaban 48 dólares al mes (o sea \$. USA. 24 a cada uno). Ya en la capital de los Estados Unidos, los "cholitos" se dieron cuenta de que sur salario era muy inferior al de sus colegas de trabajo, Cornelio, uno de ellos, fué a quejarse a la Embajada del Perú, entonces en manos de Alfredo, como encargádo de Negocios. El embajador titular, Hernán Velarde, se hallaba en París.

Alfredo amparó a Cornelio, instruyéndolo acerca de sus prerrogativas legales, y, como este insistiera en salir de casa de los Poindexter, Alfredo resolvió aceptarlo como sirviente en su casa, pagándole el debido sueldo.

La señora Poindexter, una de esas ladinas comadres washingtonianas, tal vez de las famosas y entrometidas. "Hijas de la Libertad", temible especie mucho más enjundiosa que las shakespirianas de Windsor, había, en el entretanto, escrito una "acusación" contra Alfredo, dirigida al Presidente Leguía. En dicha carta, fecha 9 de julio de 1929, hacía una pintoresca y arrabalera historia de lo sucedido, y sometía al "arbitraje" presidencial el asunto: "Como a Ud. le consta - decía-- cuando estuve en el Perú, siempre "me acerqué a Ud. en todas mis penas y mis alegrías, con la cer- 
"tidumbre de gue habia de encontrar una persona que me " escuchara con simpatia - y un juez justo. Cualquiera que "sea su decision en este asuntw, que crea Ld. que Prada tie"ne la razion o no, tendré que llevarme de su fallo".

Funcionaron átulicos $\mathrm{y}$ adulones en Washington $\mathrm{y}$ l.imát. Misteriosas carlenas de noticias. Hilos buroctíticos y politicos. Finalmente, el 8 de agosto. el Ministro de Relaciones Exteriores del Perú, Pedro Jose Rada y Gamio, dirigió a Alfredo el telecrama numero 42 , cuyo texto fuc:

"Causádonos penosa impresión incidente usterl con senora Prindexter. Stop. Esperamos satisfámala usted ampliamente y entrégucle criado. Conteste. -Rada y Gamio".

\section{Alfredo respondlió:}

"Agosto 9. Telegrama I 21 - P.os Terminos de su cablegrama $\div$ me hacen comprender fue sus informaciones solire el incirlente son inexactas. Como no puedo creer que deliberadamente guicra usted proceder en forma injusta, basando su determinación hnicamente en la antojadiza versión de la señoráb Poindexter, estoylistrosi usted me lo pide, a explicar la verdád de lo ocurrido.-Ganzáles Prada" terial:

Consultas y chichisveos en Lima. Y la réplica minis-

"Agosto I3. Telegrama número 44. En respuesta a su telegrama No. I2I, cumpla usted inmediatamente instrucciones contenido mi telegrama No. 4I.-Rada y Gamio".

Duplica final de Alfredo:

"15 de Agosto. Las ótdenes de su cablegrama son in"justas y no las cumpliré. Si amparar los derechos de un 
"ciudadano pertiano, abusado y explotado, constituye a los "ojos de usted un acto censurible en un funcionario oficial, "yo pienso de distinta manera y como no estoy dispuesto a "obedecer sus instrucciones arbitrarias, renuncio al cargo "que desempeño. Sé que este incidente es un simple pretex"to $y$ la culminación de una actitud de hostilidad latente des"de el instante en que rechacé el nombramiento de Conse"jero de la Embajada del Perú en Chile, y me negué a aso"ciar mi apellido a las desastrosas negociaciones que han "terminado con el pacto infame que acaba usted de suscri"bir. No me sorprende que mi actitud de hoy le parezca re"prochable: mal puede comprender mi afán justiciero de "proteger los intereses de un peruano humilde, quien como "usted ha fracasado en la defensa de los más altos y sagra"dos derechos del Perú. He hecho entrega de la embajada "al Consejero don Isaias de Piérola, a quien he presentado "al Departamento de Estado cono Encargado de Negocios "ad interim.-González Prada".

\section{Contestación iministerial:}

"Agosto 16. Lima. GQR o38 p.m. IUreplac. WNDC. Para González Prada: Aceptada remuncia. Rada y Gamio". Ya el día anterior, Alfredo se había dirigido al secretario de Estado Mr. Stimson devolviéndole su tarjeta de pase como diplomático y presentando al señor Isajas de Piérola. A éste, que se hallaba en White Oak Shade, New Canaan Connecticut, le dirigió un telgerama urgente diciéndo:

"He renunciado hoy y siendo usted el siguiente en ran"go en la Embajada se convierte en encargado de negocios "automáticamente. He notificado al Departamento de Esta"do y a Relaciones Exteriores de Lima. Como hay asuntos 
“importantes pendientes con el Departamento de Esta"do, haga el favor de venir a Washington tan pronto como "pueda. Le telefonearé esta noche a las nueve, tiempo del "Este. Mis mejores consideraciones. Cronsálcz Prada".

Cren útil recordar aquí el texto de otra renuncia de Alfredo, quince años antes, cuando el solpe de Fstado del coronel Benavides:

"Lima. 18 de mayo de I9I4.-Señor Oficial Mayor del Ministerio de Relaciones Exteriores. S.O.M. - El acuerdo tomado por el Congreso Nacional me obliga a elevar a US. ia renuncia del puesto que desempeño. Dios guarde a US. Alfredo González Prada".

\section{A lo que contestó el Ministro:}

"Lima, 18 de mayo de Igr4.-Destitúyase al oficial $\Lambda u$ xiliar del archivo de limites don Alfredo González Prada, y no siendo necesario, para el buen servicio de la oficina citada la provisión de este empleo, suprímase dicho cargo en el proyecto de presuptiesto general de la República, que debe ser remitido a da próxima lli legislatura,-Rúbrica de S.E. Gazzani".

Y la aclaración de Alfredo:

"Lima, Ig de mayo de Igr4. Señor Director de "La Frensa". S.D.-Ruego a usted que se sirva insertar en su periódico esta declaración necesaria: no me parece muy seria la actitud de las personas que me destituyen de un puesto con posterioridad a la presentación de mi renuncia. Soy de Ud. atto y S.S. Alfredo González Prada".

En 1929, "La Prensa" de Lima estaba en otras manos. En su edición del i 8 de agosto, domingo, lanzó una versión 
tendenciosa de lo ocurrido. Con ello se inició el escándalo continental.

El dia 21, "El Morcurio" de Santiago, Chile, "The Sun", "The Herald and Tribunc", de Nueva York, el "Washington Post", de Washington, y otros diarios publicaron el cuento con sensacionales caracteres. El 25, el " $S_{u t h-}$ day' Star" cle Washington encabezaba la suya así: "Pcrhaps inside story may never be told of how an Ex. Ambassador's wife lost a good seriant and a diplomatic a good post".

Alfredo empezó a recibir innumerables felicitaciones. La primera de todas, desde Nueva York, del dibujante Julio Málaga Grenet, decia así: "Abrazaso formidable por haber hundido en m... a a Pedro José. Como en el cuento de "Los Canastos" de Palma, ha restablecido usted el equilibrio universal. En este momento le escribo lleno de entusiasmo y admiración".

Mas significativa es la de Carlos Concha, más tarde Ministro de Relaciones Exteriores del Perí y Embajador en Chile, entonces destertados en uño de sus párrafos decía:

"Era casi un milagro que le respetarant, a Ud. esas gentes indignas del gobierno de Lima, que no tienen el menor concepto de la honradez y la decencia... . Me alegro infinito de que esté usted de acuerdo conmigo al juzgar el Tratado Figueroa-Rada. Su silencio me lo hacia entender asi. El que haya podido suscribirse semejante pacto, da idea del grado de abyección a que se ha llegado en el Perú". (fechado el 22 de agosto, en Yale University).

Don Rafael Larco Herrera le dirigió una significativa carta desde Chiclin, en el Perí.

Existe tna laguna en mi información, referente al poeta Chocano. Descle Santiago, Chile, donde residia, dirigió a Alfredo un cable diferido, depositado a las 6.57 , del 30 
de azosto, en que decia: "Cablegráfieme dirección. Escribole. Santos Chocano". - Prada no contestó.

Los grupos de proscritos peruanos de todos el mundo saludaron el nombre de Alfredo como una renovada bandera de rebeldia. Entre ellos, el Comité del APRA, sección de Paris, sobre la firma de Luis E. Heysen, Alfredo Gonzáles Willis, Wilfredo Rosas, (iregorio Castro, Horacio Guevara, y José Z. Ochoa.

Yo estuve la tarde del 18 de agosto con doña Adriana, en Lima. Las visitas fueron pocas, pero entusiastas. I os de la "vieja guardia" de don Manuel. Ella, la madre, apenas hizo comentarios. Un "Era tiempo, ahora podrá hacer su obra" fué lo mas explicito.

El apellido de Gonźlez Prada flotaba al viento, como airón de gruerra.

Alfredo no quiso aprovechar la ocasión.

En la noche del vicrnes 6 de setiembre, en compañia de Elizabeth, su esposa, se emluarcaba a bordo del "Ilc de Fran$c e "$ con rumbo a Europa.

En el horizonte se levantaba ya la fevolución que iría a derribar a Leguía Mâsi cercana atun, la espantosa crisis de Estados Unidos, el célebre y hasta ahora irrestañable crack del Wall Street.

\section{V}

E1 22 de Agosto de 1930 se pronunció, en Arequipa, al sur del Perú, el Comandante Luis Sánchez Cerro, quien, pocos meses antes, había sido ascendido y destinado a dicho lugar por el Presidente Leguía. La crisis de Wall Street habia derribado ya al gobierno de Siles, en Bolivia, y no permitió al del Perú, defenderse. En la madrugada del 24 al 25 de agosto, la guarnición de Lima, obtuvo la di- 
nision del Presidente. El Perit iba a sufrir una profunda, contradictoria y tremenda experiencia.

Aliredo se hallaba en Fstocolmo cuando recibio la noticia. Fucuentro en un recorte de "El Dia" de Montevideo, correspondiente al 31 de agosto, la noticia de que Alfredo inabia sido nombrado agente confidencial de la Junta Militar de Gobierno ante el gobierno de Londres. El 19 de setiembre, según dije. se le designaba Enviado Extraordinario y Ministro Plenipotenciario ante dicha Corte. Ese mismo dia eran nombrados Embajador en Buenos Aires, el Dr. Felipe Barreda y Laos, y Ministro en Francia, el Dr. Francisco Garcia Calderón. La Junta se hallaba en plena luna de miel con la Democracia y su hermana, la I_ibertad. E1 lenguaje de los discursos oficiales habria sido maratiano si no hubiese olido ya a restauración. Alfredo sólo percibió el eco de la revolución, desgraciadamente truncada casi en sus comienzos. Por eso, el contandante Sánchez Cerro hubo de abandonar el poder el I. de marzo de I93I. Encuentro un detalle de deliciosa ingenuidad en lā prensa norteamericana se dió la noticia del nombramiento de Alfredo haciéndolo aparecer como autor de mi "Don Manuel", "dealing with the life of the Peruvian patriot, who was his father. Written in Spanish this will shortly be translated into English".... Shortly: muy en breve..... Encuentro tuna mención parecida en el "Washington Daily Ners", del jueves 25 de setiembre de 1930 . En el "Yorkshire Evening Nerces" de Londres ( 44 \& I5 Trinity St.) del I6 de diciembre de 1930, un redactor escribe: "I was charmed to meet the Peruvian Minister in London. He is young and most able, and his delighful American wife soon adorn our London diplomatic society. The Minister's name Mr. González Prada". 


\section{$-34-$}

Sánchez Cerro, en aquella primera etapa, anduvo titubeando entre un radicálismo 1890 y un conservatismo 1900 . No se sabía bien su exacta posición, hasta que la definio durante su campaña presidencial de igзs. Cuando fue a Europa, en voluntaria proscripción, en abril de 1931, ofreció un banquete en Paris en el Pabellón de Armenoville, a un grupo "de personnalités françaises et peruviennes". Contestio a su ofertorio, M. de Sillac, antiguo Ministro francés en I-ima. Entre los asistentes estuvieron Alfredo, a la clerecha de Sánchez Cerro, Francisco García Calderón, el general Cesar La Fuente, Francisco Tudela y Varela, Felipe Pardo y Barreda, el general Fernando Sarmiento, el comandante Gálvez, Ventura Garcia Calderón, Andrés y Juan Alvarez Calclerón, Enrique D. Barreda, Enrique Goytizolo, Eduardo Lanatta, el comandante Rabines, el comandante Escurra, el Mayor Alayza, el comandante Guzmán Marquina, los señores Althaus, Mould Távara, Espinosa Cáiceda, $y$, entre los franceses, Gabriel Hanotaux.

Alfredo empezó a entender ahí por qué en 1929 los civilistas de Europa solíancllamar a Sánchez Cerro, "el cuchills".

Por esos dias, llegó, de Alemania, a Londres, Haya de la Torre, candidato del flamante Partido Aprista Peruano a la presidencia del Perú. Nadie de los personajes oficiales peruanos en Europa, le quiso prestar atención. "Joven, revolucionario... y pobre": iqué hacer con tamaña trilogia! Alfredo lo alojó en la misma Legación. "Un candidato a la Presidencia es, por definición, uno de los más eminentes ciudadanos de un país, y mi deber como representante de éste es atender y servir a todos sus hijos, máxime a quienes. el pueblo estima como merecedores a regir sus destinos", fue la perentoria respuesta de Alfredo a quienes le critica- 


\section{$-35-$}

ron aquel acto Guardo muchas anécdotas de aquellos dias de Haya en casa de Alfredo. La vieja estimación se hizo fuerte amisiad - no rota jamis.

En "lil Comcrcio" de Lima, del 12 de mayo de 1931 , hay $u 11$ elogio a la actitud de Alfredo durante los procesos internacionales de la época de Leguia. El viejo adversario acogió, quizá por vez primera, semejante juicio, firmado por Carlos E. Grimez Morón.

Antes de eso, el lunes 13 de octubre de 1930 , en un diario vespertino limeño, "Crítica", nacido a raiz de la caída de Leguia, se publicaba una "Crónica de Saira", titilada "Nucstro cucrpo diplomático" en que se decia: "Convengamos en que por un García Calderón, un Rey y (sic) Castro, un Belauinde, o un González Prada, hay veinte Cornejos, cincuenta Freyres y doscientos del Solar".

Por aquellos dias, el 8 de diciembre de 1930, Alfredo pronunció un discurso, mas bien una conferencia, sobre la Quinina peruana, a raiz de la exposición y conmemoración del tercer centenario de dicha medicina, celebrada pomposamente en I_ondres. Reproducimos el texto integro de su trabajo, uno de los nais concienzudos queshay sobre la materia. Durante semanas, estuvo consultando, con esa pertinacia y agudeza que fueron sus caracteristicas, libros y manuscritos del Museo Británico. Tengo ante mi, sus notas. Ellas descubren cabalmente la pulcritud impar de este gran estudioso. Por cierto, ningún Ministro peruano hizo jamás j)arecido esfuerzo para sólo un discurso de efemérides.

Entre las congratulaciones recibidas por Alfredo, figuran varias de Jesuitas. ;A tout Seigneur, tout honneur!

Se habló, entonces, en Lima, de la candidatura de Alfredo a la presidencia. Nunca me dijo ni me escribió nada al respecto. He visto a través de su archivo algo, pero no es 


\section{$-3^{6}-$}

secreto que me pertenezca. Se (pués me lo dijo persona que anduvo en ello) que varios allegados a la Junta de golierno de marzo-octubre $19.3 \mathbf{I}$, pensiron en Alfredo como una transacción. Repito, el comandante Jimenez lo tuvo muy presente. Pero Alfredo prefirió cumplir a conciencia su papel, entregándose a su misión como él se entregaba a aquello que se ponía entre sus manos.

Nombrado Delegado a la I.iga de las Naciones, no tardó en desarrollar su vigilante actividad en un sentido rel todo diferente al consuctudinario entre los magistrados nacionales. Cuando México fue invitario a adherirse a la I.jza. los miembros latinoamericanos de esta decidieron que Alfredo asumiera su representación para expresar la alegria de todos por dicho acnntecimiento. El $\mathbf{I}{ }^{\circ}$ de Diciembre de I930 firmó la Convención para prevenir la gruerra.

En "le Temps" de Paris, del 12 de diciembre de I93I se da cuenta de la Sesión en que Lord Cecil, Aristide Briand. Salvador de Maclariaga, Mr. de Chlapoki (por Inglaterra. Francia, España y Polonia, respectivamente) se pronunciaron en el sentido delfacilitar un acuerdosentre China y Jafón, y el BarónJVon Mutius,l de Alemania, declaró que ese era también el sentir de su gobierno (entonces en manos del desdichado Hindenburg). Alfredo propuso una resolución adicinnal, cuyo texto, directamente traducido del francés dice asi :

"Nada en los textos adoptados debe ser interpretadn como contrario a ciertos principios que son los siguientes:

I. Ningún Estado tiene el derecho de ocupar militarrnente el territorio de otro para asegurar el cumplimiento de algún tratado.

2. Ningún Estado tiene el derecho de impnnerse a otro mediante la invasión por tropas del primero, ni entablar en- 
tonces negociaciones directas acerca del alcance $y$ valor jurídico de las convenciones preexistentes entre ambos Estados.

3. E1 ejercicio del derecho que incumbe a todo Estado, para asegurar la protección de las personas y los bienes de sus súbditos, debe estar limitado por el respeto a la soberanía del otro Estado; ningún Estado tiene el derecho, para asegurarse tal protección, de autorizar a sus fuerzas militares a penetrar en el territorio del otro estado con el objeto de realizar operaciones de policía.

4. El hecho de que un Estado posea derechos, acreencias, concesiones de orden económico, etc. con respecto a otro Fstado, no otorga al primero de dichos Estados el derecho de ocupar militarmente territorios o apoderarse de bienes del Estado deudor. Todo cobro coercitivo de deudas debe ser excluido, conforme a los principios admitidos en la segunda conferencia de la paz" (Io de diciembre de I93I).

Además, dijo entonces Alfredo, en nombre del Perú, que las medidas excepcionales adoptadas por el Consejo de la Liga, a propósito de la ya iniciada lucha chino-japonesa, no debían ser interpretadas como renuncia a los derechos internacionales que se refieren a la defensa de los derechos e intereses de los países débiles, y que, sólo dentro de tales límites, prestaba su aprobación a lo propuesto. En "La Pren$s a$ " de Buenos Aires, del I de diciembre de I93I se reproduce in-extenso el discurso de Alfredo. En todos los diarios del continente se hizo eco a aquella actitud. El Foyer International des Etudiants (93 Bul. St. Germain, Paris) le envió una calurosa felicitación. En el Perú el llamado "periodismo serio", olvidó "benignamente" la actuación de quieri atraía para el Perú, en esos momentos, el aplauso continental. Porque el significado de aquel discurso era la primera franca respuesta y rectificación a la política internacional 


\section{$-3^{8}-$}

entreguista sostenida en la Conferencia Panamericana de I.a Habana, en 1928 , y a las inocuas posturas en Ginebra, a lo largo de años. Como que llegaria la oportunidad en que un delegado del Perú sirviera de sacador de castañas del inimerialismo mundial, atacando a una pequeña potencia en rudo trance decisivo. Solo "La Revista Semanal" del i4 de enero de I932, y "La Tribuna" del 21 reprodujeron las declaraciones de Alfredo. Ltuego lo hizo la prensa liberal de provincias. El diario aprista, remarci el hecho de que la gran prensa del globo - "Le Journal". "Lec Temps", "The Chicago Tribunc". "The New York Herald Tribune". "La Nación", etc., habian dado amplia publicidad a dichas declaraciones, pero......

Pero, Alfredo había renunciado ya a su cargo, en desacuerdo con el rumbo conservador, "civilista" y antipopular del nuevo gobierno.

Una vez más, sin estridencias ni teatralidades, evidenciaba su civismo inveterado y sincero.

Pocos habrian hecho eso: nadie lo hizo, apesar de que se advertía la olia de sangre que amenazaba al Perú. Tengo a la vista, por ejemplo, el carnet del "First Court", o sea primera recepción de la Corte del Rey de Inglaterra, el ig de mayo de 193 r, y las tres siguientes, en todas ellas, los González Prada en lugar de honor; y el croquis del banquete en el Palacio de Saint James, el 7 de julio, en el cual Alfredo aparece sentado a la diestra de H.R.H. The Prince of Wales, y a la izquierda de Lord Lovat, y tiene a su frente al Lord Mayor de Birmingham. Los criollos suelen permanecer profundamente adheridos a tales distinciones. Alfredo la tiró por la borda, y con ellas, por tercera vez, su carrera. A veces, recordando aquellos dias dijo: "La más profunda impresión que guardo de aquello es el asco que me daba 
Arístides Briand y sus manejos de sucia politiquería. Era abominable".

A partir de 1932, Alfredo se consagra plenamente a su carrera de albacea literario de su padre, luego, de escritor.

No emitió ninguna crítica acerba contra el gobierno de quien se apartaba. Alguna vez le oí decir: "No tengo derecho de criticar después de tan larga ausencia. Procedo de acuerdo con mis principios, y quedo en paz con. mi conciencia. Eso es todo".

Así lo hizo.

Viajó a España, residió en Francia, se dirigió al Oriente, recorrió Egipto, Palestina, Turquía, Grecia, Italia.

De vuelta en París, traía ya sus planes maduros.

Ahí le esperaba su madre, que había viajado desde Lima. Llevaba consigo, para tratar de curarlo,- a Felipe, el unigénito. Yo lo había visitado, en unión de Haya de la Torre, dos años antes, en el Hospital de Bellavista del Callao. El espléndido muchacho estaba más débil que un suspiro; pero ardian en sus cuencas los enormes ojos negros, y el perfil denunciaba $J_{s u}$ prosapia.

Murió el pobrecito, tan digno, tan inteligente, tan ya logrado, al borde de su carrera universitaria; murió el pobrecito Felipe González Prada, en París, al lado de su abuela, doña Adriana, siempre vigilante y abnegada. Fue una doble, una triple agonía: para el muchacho, para la abuela, para Alfredo, que, desde lejos, pero sin interrupción, cuidó de aquel fruto de su adolescencia apasionada.

Así quedó roto todo vínculo carnal con el futuro. Ahora no restaban sino los espirituales. En el Cementerio de Pére I.achaise reposa desde entonces el último brote de ambición terrena de un grande y trunco escritor sudamericano. 
En 1933 aparecia, al fin, un libro largamente anunciado por el propio don Manuel: "Bajo el Oprobio". Lo habia redactado el Maestro contra las dictaduras militares, pero, pensando estrictamente, en la del coronel Benavides contra quien no tituber en combatir- $y$ cron d. Alfredo. Como siempre, este no buscó la línea de menor resistencia, sino la de mayor. Lo habria podido imprimir años antes, pern entonces el ya General Benavides estaba desterrado por L.eguia y hubiera parecido cobarde; lo pudo publicar, luego, pero tampnco alcanzaba Benavides puesto destacado. Io lanzó cuando Benavides fué electo presidente de la república, otra vez por el Congreso y en condiciones irregulares, el 30 de alıril de 1933 .

Sin estridencias, Alfredo seguia siendo un rebelde, enemigo de los grandes gestos, acaso por dandysmo.

Poco antes habia publicado otro libro póstumo de su padre, cuya descifración le tomó largo tiempo: "Trozos de vida" (1932), igualnente editado en Paris. Se hallaba en plena tarea de rescatar del olvido y eísilencio la obra paterna inédita.

Con anterioridad, doña Adriana habia reeditado, en Lima, "Horas de Lucha" (Callao, 1924), "Mintisculas", "Presbiterianas". "Páginas libres" circulaban en edición de Madrid, con prólogo de Rufino Blanco Fombona.

En 1935, por encargo de Alfredo, y con prólogo mio, pedido por él, publiqué en Santiago, "Baladas Peruanas". Alfredo extrajo su texto de una colección de "Baladas" en general. Al año siguiente me envió los originales de "Anarquía", que es una compilación de artículos dispersos en diarios y revistas, reunidos pacientemente por Alfredo. Al fi- 
nal de 1936, él y Elizabeth me fueron a visitar a Chile. Doña Adriana estaba en París. Alfredo viajaba con una maleta especial, que ahora tengo, en donde guardaba los manuscritos paternos, y un archivador especial con su trabajo bihliográfico sobre don Mantuel.

En Santiago, arreglamos el plan de otro libro del Maestro: cuyo título me tocó decidirlo: "Nucias Páginas libres" que aparecería en 1937.

Estuvimos dos dias juntos en Viña del Mar, de esos dos dias, dia $y$ medio lo pasamos frente a los manuscritos del Apóstol, discutiendo asuntos conexos.

En aquel viaje, Alfredo tuvo contactos políticos, solicitados a él. Don Jorge Prado, entonces embajador en Brasil, le pidió que sirviera de enlace con los apristas desterrados en Chile, para que, a su vez, estos se comunicasen con los de Lima, a fin de infundir confianza en que su candidatura presidencial seria de total garantía para estos.

De aquel debate privado guardo algunos apuntes y documentos. Alfredo se limitó a trasmitir con esa fidelidad minuciosa y silenciosa, que él solía poner en todo lo suyo. Si después se hizo alguna publicidad, él no autorizó ninguna. Se disgustó profundamente por ello, pero apenas si tuvo una levísima queja al respecto. Si hoy hablo de esto es porque me autoriza el hecho de que se dió prematura y no siempre fiel jublicidad a este episodio, cuyos pormenores conozco a fondo.

Alfredo no quiso seguir al Perú. Lo alejaba su rechazo persistente a la situación de fuerza imperante.

Volvió a Estados Unidos por Argentina y Brasil. En Santiago apenas había podido estar, pues Elizabeth tuvo un ataque de asma y fueron a buscar mejor clima en Viña del 


\section{$-42-$}

Mar, bajo el encanto de su ciclo y al pie de sus rocas incomparables.

Regresó a Europa, llenada esta tarea, con cinco libros de su padre descifrados, copiados, ordenados y publicados.

En París había estado a cargo de la publicación de un libro que quedó inédito después de impreso: un macizo y agudo manojo de "Pcnsamientos" por Fernando Tola, que él prologó. Reproduzco el prólogo y guardo uno de los dos 0 tres ejemplares salvados de la suillotina del impresor.

Por entonces se volvió a ver con César Vallejo, cl insigne poeta peruano- conforme lo narra en su conferencia sobre él, que también reproduzco, y, como la guterria de España había estallado, encontró en París al poeta Alberto J. Ureta. Sé que Alfredo decidió la publicación del libro de este "Elcgías a Cabcza loca". Tgnoro cual fue exactamente su intervención, pero una carta de Ureta a Alfredo le dice perentoriamente, que su publicación se debe a éste.

Europa estaba convulsa. Una carta desde París me anuncia sus temóreside conflagración. Previéndolos, decidió que su madre viajara a dos Estados Unidos, a donde llegó a fines de 1936 .

Desde entonces, doña Adriana vive en Nueva York, pendiente, hoy como ayer, de sus dos amores: don Manuel y Alfredo, y consagrada a exaltar su memoria.

En París, Alfredo continuó sus búsquedas. Publicó, por aquel entonces, otros dos libros de su padre, escrupulosamente anotados por él: "Grafitos" y "Figuras y Figurones". Para algunas de las notas de este último, empleó meses y ocupó a muchas personas en Lima. Yo recibí varias indagatorias y he visto otras hechas a amigos limeños. Uno de estos, Rafael Loredo Mendívil se ocupaba continuamen- 
te en enviarle copias de los recortes, articulos $y$ documentos que Alfredo requería. edición.

No tardaba en publicar "Baladas", en primorosísima

A todo esto, había vuelto a Europa, a comienzos de 1939.

Teingo a la vista cartas con Nicanor Mujica Alvarez Calrlerón. para que este fotografiara la casa en que don Manuel vivió en Burdens. La investigación de Alfredo era implacable. Por entonces, además, había retınido material bibliográfico de consideración. del que dió una muestra en el número de la Revista Hispánica Modcrna, de la Universidad de Columbia, Nueva York, dedicado a don Manuel.

Estalló la guerra. El pánico entre los extranjeros de París fue espantoso. Altredo y Elizabeth resolvieron esperar a que se colmasen los primeros buques, y volver en el "Prcsidcnt Harding", transatlántico de r4.00o toneladas, perteneciente a la marina mercante norteamericana.

Era ya octubre de I9.39, un mes despućs del estallido.

No eran dias de paz. 598 personas viajaban en aquel huque.

Hacia el amañecer delc I3 ldecoctubre" el "President Harding" recibió un SOS del mercante inglés "Heronspool." a quien un submarino nazi habia torpedeado la noche anterior, a 300 millas de la costa irlandesa. Los sobrevivientes subieron al puente del transatlántico: elocuentes espectros, heraldos del drama en marcha.

El mismo I 3, otro patético SOS del petrolero francés "W. Enile Miguet" conmovía a los pasajeros del "Presi-. dent Harding”. Su tripulación fué salvada por otro barco, el "Black Hazek".

Poco después, inesperada tempestad hinchó el mar de olas, con espectacular iracundia. De pronto, a las 9 y 36 p.m. 
violentísima sacudida hizo crujir al orgulloso "steamer". Mrs. Elizabeth Johnson, de Palisades Park, N. Jersey, que se hallaba durmiendo en la litera superior de su camarote. sintió que algo la arrojaba al suelo. Ias señoras Katherine Van Dyke, de Pasadena, y E. Chandler, cuya plácida digestión habia buscadlo el ambiente del "smoking room", rodaron contusas por los suelos. Wallace, el negro chofer de Alfredo, sufrió un golpe que casi le fractura el cráneo. "En el choque entre la cabeza de Wallace y el barco, supongo que este ha salido perdiendo" comentaba risueño Rafael Loredo en carta a Prada. Alfredo y Elizabeth resultaron también heridos, pero mas que físicamente, en el alma.

Mr. Paul Van Zeeland, expremier de Bélgica, su esposa y dos hijos, figuraron entre los contusos.

En el "New York Times" del 22 de octubre, asi como en el "The Herald and Tribune" de la misma fecha (páginas 38 y 24 , respectivamente) se da cuenta de la llegada del "President Harding" a puerto: de su pasaje, Io heridos graves fueron al St. Vincents Hospital, it al Marine Hospital, I al Newlioork CHospital, 2 al I.enox Hill Hospital, 6 al FrenchJHospital, 3 al Columbia Presbyterian Medical Center, 27 a sus respectivos hoteles. Entre los $6_{3}$ heridos habian varios latinoamericanos: La señora Artel de Altah, de Chile, la señora Alvarez Nurens, de Cuba, Alfredo no informó de su herida en la rodilla, ni Elizabeth de sus contusiones en el cráneo.

Tampoco se dijo nada de que, durante el temporal, la tripulación después de beberse un cargamento de champaña que llevaba el buque, halló menos dramática la situación, de lo que convenía.

La muerte aleteó por varios dias sobre la cabeza de A1fredo y Elizabeth, aquella vez. 
Durante el resto de sus dias, no pudieron librarse del trauma psíquico consiguiente - sobre todo Alfredo.

No es fácil pasar frente a los linderos de la Muerte sin pagar alto tributo. Alfredo lo pagó y - muy caro.

Después de aquel regreso se cledicó pasajeramente a unos negocios de café con la Frey Weaver Co. de Pennsylvania (carta de 2I dic. 1939) y a publicar en Buenos Aires otros dos libros de don Manuel: "Propaganda y Ataque" y "Prosa Mcnuda", cuajados de oportunas y minuciosas notas aclaratorias. El subvencionó a los editores, conforme cartas a la vista.

Con Carlos García Prada colaboró a preparar la magnífica "Antología poética", que constituye el tomo I de la seric Clásicos de América que publica el Instituto de Literatura Iberoamericano.

los amigos le reclamábamos su propia obra, pues yo supe, por Elizabeth y doña Adriana, en 194I, en Nueva York, que Alfredo todavía escribía cuentos y hacía traducciones de versos. Las de Geneviève Taggard son sencillamente acabadas.

No podía ya viajar fuera de los Estados Unidos. Al respecto sufrió un profundo disgusto cuando la Inmigración se negé, por largo tiempo, a reconocerlo como pertano, en vista de que había nacido en París, y a pesar de haber sido Representante diplomático del Perú en Washington. Para Alfredo, dueño de una sensibilidad hiperestésica, aquello significó rudo golpe. Cuando al fin puclo solventar su situación, ya era un poco tarde.

A fuerza de porfía logramos que publicara en " $L a N u e$. ra Democracia" dos pequeñas parábolas - "La Cana" y "Las tres dimensiones". Aparecieron cartas styas en revistas pequeñas. "Cultura peruana" de Lima, publicó un cuen- 
to suyo en 1942. En noviembre de 1941 se decidió a romper su inédito lanzando el librito "Un crimen perfecto". verdadero modelo de investigación acuciosa, de humor y de estilo. Ne cupo el honor de revisar su último origina!. desde Chile, y de recibir el primer ejemplar, en Washington. A propósito de la crítica que Alberto Rembao publicó sobre "Un crimen perfecto", Alfredo le dirigió una carta, fechada el 12 de mayo de 1942, en Pasadena, California, que no resisto a la teintación de publicar.

"Querido Rembar: Veloz y amable me llego ayer su "comentario de mi "Crimen perfecto". Gracias por todo: "por esas palabras tan magnánimas, y también por esos ho"nores tipográficos de la página entera. No se imagina con "que penetración tan perspicaz ha coincidido usted con mi "pensamiento en aquello de la presencia de mi padre. "Hijo "albacea que vive en la presencia del padre". Si supiera us"ted cuan cierto. $Y$ también el reverso que en el fondo es "identidad con el anverso padre que vive en la presencia "del hijo. Este constante existir entre papeles que no cesan "de ser inéditos: este diario contactócon un muerto que "continúa viviendo en lacpresencia der sus pensamientos au"tógrafos, este ininterrumpido hurgar entre manuscritos que "me trasmiten su mensaje sin fin, todo esto significa una "presencia de ultratumba que a muy contados toca experi"mentar en la vida. Acusa usted un penetrantísimo espíritu, "querido amigo, al haber enfocado tan certeramente su ra"yo de luz en una penumbra cuya intimidad sentía yo muy "mía, muy esotérica y muy a cubierto de mundanales atis"bos. Le felicito, sutil Rembao, al mismo tiempo que le repi"to mi agradecimiento por sus generosas líneas".

En esa misma carta, que debo a la gentileza de Rembao, hay algo sobre mí, que después explicaré: "Se nos va 
I tuis Alberto. Pero regresará. Esto es como la boca de Venus, que decia taciano: dientes capaces de morder...... pero miel bajo la lengua. No es posible vivir bajo la férula de los generales y doctores sulamericanos".

Con lo cual, entramos a la última parte, la de su psicologia, valuacion $y$ muerte.

\section{VII}

Los últimos proyectos de Alfredo eran publicar " $E l$ Tonel de Diogcnes cono piedra angular de todo lo dicho sobre y escrito por su padre; después "Ortometria" y arreglar, con Garcia Prada un volumen de "Escritos Escogidos" cuyo plan dejó terminado, Y que debería llevar prólogo mío. Luego, reanudaria su propia obra- y buena copia de apuntes hay entre sus papeles. Además, queria publicar unia Bibliografía de su padre, con mas de mil papeletas, pero deseaba que alguien quisiera suscribirla, no él. Le propuso esto a Cosme Orraca, con motivo de la tesis que para su doctorado en Filosofia, en Colunibia University, se hallaba preparando. Or raca declinó hidalgamentes Igualmente, queria publicar un trabajo sobre "El Polirritno de Golizáles Prada", y le propuso a nuestro común anigo y notable critico de arte y escritor, Felipe Cossio del Pomar, que lo firmara, pero Cossio declinó también semejante cosa. Alfredo no quería aparecer como crítico ni bibliografo de su padre, aunque nadie lo ha sido ni será mejor que él.

El estudio sobre el polirritmo aparece inserto en este volumen. con las lagumas que Alfredo dejó, pues no está terminado. Ia Bibliografía aparecerá a stı tiempo.

Alfredo me propuso en Washington, en noviembre de 1941, que me quedara en los Estados Unidos para fundar 


\section{$-48-$}

una revista: "Tengo alrededor de diez mil dólares, pero no quisiera avisos: mi única condición es que usted esté conmigo, aquí". Hube de postergar la idea, para mi regreso. Regresé muy tarde.

Me llamó la atención en Alfredo durante los dias que nos vimos en noviembre-diciembre de I94I, en Nueva York y Washington, y en enero de 1942, en Pasadena, California. cierta nerviosidad, que antes no le era peculiar.

Estaba muy delgado. Comía poquísimo, con gran extrañeza de su madre que se esforzaba en incitarlo a alimentarse mejor. A menudo un plato de arroz con huevo frito evidente nostalgia limeña,-constituía todo su menú.

Había indudable nerviosidad en sus gestos. Algún trauma había fundido aquel espíritu siempre tan animoso y alerta.

Le gustaba encerrarse, huyendo de la gente. A menudo, amigos intimos, de la infancia, que venían del Perú, sólo se comunicaban con él por teléfono, pues rehuia el contacto directo.

Cuando vivia al lado de $\mathrm{su}$ madre, mientras Elizabeth pasaba alguna breve temporada al lado de la suya, materialmente Alfredo no asomaba durante semanas fuera del departamento de doña Adriana, en el piso i 2 de 629 West I 73 Street, desde el cual se divisa el Hudson, como una cinta tendida entre Manhattan y New Jersey.

Ahí, con doña Adriana, devota permanente de su Gran Muerto, vivía como un niño anacoreta, con su máquina de escribir y sus libros. Virginia Pena Salinas, una muchacha ancashina, que doña Adriana llevó a París y trajo a Estados Unidos, desde Lima, - veinte años de sólida y silenciosa devoción a los Prada- preparaba bocados favoritos que 
Alfredo no siempre comía. De su última estancia en Lake Placicl habia traído una gata "de ọjos tremendos" - Angama. $y$ el vicjo perro de Elizabetl, ambos miembros adicionales de aquel "home" siempre en espera del hijo trashumante, pero fidelísimo.

A principios de 1943, algo torturaba a Alfredo. Un médico le vaticinó que algo raro había en uno de sus oídos, y yue corria el riesgo de convertirse en absceso. L.tuego, le dijeron que cl absceso existia y que si reventaba podía morir en $\mathrm{cl}$ acto o enloquecer. Fue espantoso.

Veo en una carta de abril de 1943 a Felipe Cossio que le dice melancólicamente, como quien se despide de una ilusión: "Ya Luis Alberto no viene. He perdido la esperanza de que sea posible". En mayo yó recibi una carta suya en que me habla de "este póntico destierro en que vivo", con una nota de terrible melancolía. Para contrarrestarlo, le escribi una carta animosa, lablándole de planes para el futuro. Esa ya no tuvo respuesta.

Algo extraño fernientaba en él. Apelog la lista de sus lecturas, según sus propias notas en que se, ve que en mayo su depresión le alejó de stu número habitual de lecturas.

En octubre de 1942, leyó: "The last time I saw Paris" por Patul Elliot: "Sing Sing doctor" por Amos O Squire: "The incredible Marquis Alerander Dumas", por Herbert Gorman; "T'oulouse Lautrcc", por Gerstle Mack; "Until the day break", por Louis Bromfield": "Le ronge ct le noir", por Stendhal, y "Alardes y dcrranas", por Rafael Loredo; en Noviembre, "The coming battlc of Gormany", por Wiliams B. Ziff: "El inglés de. los gucsos", por Benito ILynch: "Un sudamericano en Nortcamérica", por Luis Alberto Sánchez; "Carlos Baca Flor", por Emilio Delboy, y "Hernán Cortés", por Salvador de Madariaga; en diciem- 


\section{$-50-$}

bre, "Behind both lines", por Harold Denny, y "GBS: a full length portrait", por Hesketh Pearson. En I943, en enero, "Zola and his time" por Matthew Josephson: en felorero, "Two suraized". por Guy Pierce Jones: en Marzo, "Appeascment child", por Thomals J. Hamilton; "See here, Prizate H.", por Marion Hargrove; "The art of secing", por Aldous Huxley; "Juan Santos , el Inwencible", por Francisco A. Loayza: "Mcmories of happy days". por Tulien Green; en Abril: "Tunis expedition", por Darryl F. Zanuck; "Native son", por Richard Wright; "Vicnto y grani$z 0^{\prime}$, por Juan Iniguez Vintimilla; "Lost train from Berlin", por Howard K. Smith; "Dress rehearsed", por Quentin Reynolds; "Sucs to Singapore", por Cecil Brown. En mayo de 1943: "One world" por Wendell Wilkie: "Unlocking adventure", por Charles Courtney y "Walden". por Thoreau.

Esta illtima lectura tiene su historia. Yo había pulblicado un artícul:: sobre Thoreau en la "Revista de Litcrat"ra ïeroumericuna", en el cual comparo a menudo a Don Manuel con Thorealt Alfredo me escribió entusiasta, porque él y Elizáleth habian colncidido en que era una verdadera "trouvaille". Eso fué hacia mayo de 1943.

El mal se hizo entonces agudo. Usaba muchas sulfas. Un detalle inocente aceleró su fin: su íntimo amigo C.G.C. le mostró un artículo sobre el efecto de las sulfas en el sistema nervioso. Entre morir y volverse loco, Alfredo decidió suprimir el último término del dilema: meticulosamente arregló sus papeles: los confió a un amigo: y una vez hecho esto, hizo creet a quienes trataban de disuadirle, aunque creyendo que se trataba de un estado transitorio, de que al día siguiente volvería a discutir con ellos. "Mañana. a las nueve tenemos otras cosas que arreglar". No cumplió esta 
cita - acaso la primera que dejó sin asistir. A las 3 de la madrugada, desde el departamento en el piso 22 del Hampshire House frente a Central Park, donde vivia, pegó el falto definitivo. Era el 27 de junio de 1943 . No había cumplido los 52 años.

Descansa en el Green Wond Cementery de Broolilyn. El 22 de abril de 1944 fue a reunirsele, en la tumba recina, Elizabeth.

Fitel a su deber de riuda y madre, de albacea de tuna insigne roluntad en plena luz, y de otra que no alcanzó a irradiar con plenitud la propia, doña Adriana sobrevive, dedicada al único empeño de hacer por los dos - Manuel y Alfredo - lo que los dos habrian querido cumplir esencialmente. Debo agradecerle que me haya dado la oportunidad de seguir cooperando con/ ella en obra que me toca tan de cercal.

Porque creo que Alfredo González Prada fue el escritor mejor dotado de espiritu crítico, de cultura y de amor a la palabra, a la exactitutd y al matiz, de toda su generación, una de las altas de nuestra literatura. Porque todo lo que hizo liera el sello de una pulcritud implacable. Porque empezaba a recuperar sul propio dominio como escritor y volvia ya a ejercer su propia carrera, después de vcinte años cumpliendo con el gran legado paterno. Porque basta leer las páginas siguientes para aquilatar todo lo que con él se fue, y todo cuanto pudo haber sido. Cosa bella $\mathcal{C}$ mortal, passa e non dura.

Nueva York, 3 de octubre de 1945.

Luts Aliberto Sánchez. 